\title{
Erratum: Development of potent monoclonal antibody auristatin conjugates for cancer therapy
}

Svetlana O Doronina, Brian E Toki, Michael Y Torgov, Brian A Mendelsohn, Charles G Cerveny, Dana F Chace, Ron L DeBlanc, R Patrick Gearing, Tim D Bovee, Clay B Siegall, Joseph A Francisco, Alan F Wahl, Damon L Meyer \& Peter D Senter Nat. Biotechnol. 21, 778-784 (2003)

In the legend to Figure $4 \mathrm{~d}$ on page $781, \mathrm{cIgG} \mathrm{Ag}^{-}$should be $\mathrm{cAC10} \mathrm{Ag}^{-}$.

\section{Corrigendum: A model of molecular interactions on short oligonucleotide microarrays}

\section{Li Zhang, Michael F Miles \& Kenneth D Aldape}

Nat. Biotechnol. 21, 818-821 (2003)

In the legend to Figure 1 on page 819, text in parts $\mathbf{b}$ and $\mathrm{c}$ was transposed. The legend should have read as follows:

(b) Weight factors. (c) Nearest-neighbor stacking energy. These stacking energies weakly correlated $(r=0.6)$ with that found in aqueous solution $^{8}$, and are smaller in magnitude.

In the legend to Figure 2 on page 820, figure parts were referred to incorrectly. The legend should have read as follows:

Accuracy test. Known concentrations of 14 'spike-in' genes are compared with those obtained from (a) PDNN, (b) MAS5.0 and (c) dChip. Each line represents a gene in 14 samples. The microarray raw data were obtained from the ' 1532 series' human data (see Methods for URL). For genes other than the 'spike-ins', standard deviations (s.d.) versus the averages of the log-transformed expression levels are shown in $\mathrm{d}$, $\mathrm{e}$ and $\mathrm{f}$ as determined using PDNN, MAS5.0 and dChip ${ }^{7}$, respectively. Each of these figures contains 12,474 genes; top half shown in red. 